\title{
The effect of lead acetate administration to the uterine malondialdehyde level and endometrial thickness in albino rats (Rattus novergicus)
}

\author{
Novita S.E. Diantini, ${ }^{1}$ Setyawati Soeharto, ${ }^{2}$ I W.A. Wiyasa ${ }^{3}$ \\ ${ }^{1}$ Dharma Praja Academy of Midwifery, Bondowoso, Indonesia \\ ${ }^{2}$ Department of Pharmacology, Faculty of Medicine, Universitas Brawijaya, Malang, Indonesia \\ ${ }^{3}$ Department of Obstetrics and Gynecology, Faculty of Medicine, Universitas Brawijaya, Malang, Indonesia
}

\section{ABSTRACT}

Background: Indonesian seawater has been found to contain a high level of lead acetate and tends to become toxic. The previous study suggested lead acetate exposure could be harmful to many organs including the brain, liver, heart, as well as the reproductive system. This study aimed to analyze the effect of lead acetate on both the uterine level of malondialdehyde (MDA) level and endometrial thickness in female Wistar rats (Rattus norvegicus).

Methods: Twenty-four rats were divided into 4 groups: 1 control group, and 3 treatment groups that were given lead acetate at 30,100 , and 300 ppm p.o./day for 30 days, consecutively. Rats were sacrificed; the uterus was isolated and processed for both MDA level measurements (using TBARS and a spectrophotometer) and histopathology using hematoxylin-eosin (HE) staining.

Results: There was no significant difference in mean MDA level between the control and lead acetate administration groups. There was a reduction in endometrial thickness from $352.6 \pm 81.88 \mu \mathrm{m}$ in the control group to $323.5 \pm 90.67 \mu \mathrm{m} ; 313.6 \pm 40.30 \mu \mathrm{m}$; $303.4 \pm 62.75 \mu \mathrm{m}$ in 30,100 , and $300 \mathrm{ppm}$, respectively. Consequently, spacious uterus was observed reflects the endometrial damage, including the decrease in the size of the epithelium, columnar, stroma, and lumen in the whole part of the uterus and these differences in uterine thickening was considered statistically significant $(p=0.005)$.

Conclusion: Lead acetate could reduce the thickness of the endometrium but had no effect on the level of MDA in the uterus.

Keywords: endometrial thickness, lead acetate, MDA, uterine

pISSN: 0853-1773• eISSN: 2252-8083 • https://doi.org/10.13181/mji.v27i3.2031 • Med J Indones. 2018;27:150-4

- Received 06 Jun $2017 \bullet$ Accepted 08 Aug 2018

Corresponding author: Novita S.E. Diantini

vita.diantini@gmail.com

Copyright @ 2018 Authors. This is an open access article distributed under the terms of the Creative Commons Attribution-NonCommercial 4.0 International License (http://creativecommons.org/licenses/by-nc/4.0/), which permits unrestricted non-commercial use, distribution, and reproduction in any medium, provided the original author and source are properly cited. 
Lead acetate exposure is a dangerous issue worldwide. In Indonesia, more than 0.03 ppm lead acetate contamination in bodies of water has been determined. ${ }^{1,2}$ This condition could lead to contamination by lead acetate in the drinking water, fish, and food entering the human body and may result in damage to both organs and cells. ${ }^{3}$ Recent studies suggested that the exposure of lead acetate poses a serious threat to all systems in the human body. One of the systems that heavily affected is the reproductive system, which is one of most sensitive and complicated system in our body. Lead acetate could affect various organs and both cellular and subcellular processes that comprise sophisticated reproductive systems in the body, including the gonadotropin-releasing hormone (GnRH) axis, hormone regulation, the uterus, and endometrial thickness. ${ }^{4}$

Lead acetate derives its toxicity by enhancing a reactive oxygen species (ROS) and causing an imbalance in the level of oxidants and antioxidants thus lead to oxidative stress. This condition can progressively damage the lipid membrane and deoxyribonucleic acid (DNA) in line with increases in the MDA level. ${ }^{5}$ The presence of this MDA protein is a marker of oxidative stress, released by the process of lipid peroxidation. In addition, exposure to lead acetate induces an unstable state in the cells and MDA is released as a marker of "danger cells."

From a reproductive perspective, the damage caused by lead acetate is not only at the reproductive organs but also the function of the hypothalamus-pituitary gland. ${ }^{7}$ However, the exact mechanism by which lead acetate causes specific organ damage has not yet been elucidated. Therefore, this study aimed to analyze the effect of lead acetate to uterine MDA level and endometrium thickness in female Wistar rats.

\section{METHODS}

\section{Experiment}

Female Wistar rats were used for the study. Rats were 10-12 weeks old, weighed 100-200 g, both obtained and maintained from the Pharmacology Laboratory of Universitas Brawijaya in Malang, and were acclimatized. During the experiment, they were housed under standard conditions with standard feed and drinking water provided ad libitum. Twentyfour rats were divided into four groups $(n=6)$, consisting of 1 control group and 3 treatment groups. The three treatment groups received lead acetate trihydrate (Merck) dissolved in aquadest with a dose of $30 \mathrm{ppm}, 100 \mathrm{ppm}$, and $300 \mathrm{ppm}$. Thirty ppm was used as the minimum standard for lead acetate consumption in humans, and subsequent doses were calculated by the arithmetic approach. ${ }^{4}$ Lead acetate was given per day via lavage for 30 days, whereas the control group was only given aquabidest via lavage. On the 31st day, a vaginal swab was performed to evaluate the estrus cycle. Rats were sacrificed during the proestrus phase under anesthetic using an intramuscular (IM) injection in the thigh with $1 \%$ ketamine at a dose of $0.2 \mathrm{~mL}$. The experimental protocol was approved by the Ethics Committee of Universitas Brawijaya No.261/EC/ KEPK_S2/06/2016.

\section{Uterine MDA level measurement}

Uterine tissue samples were cut and crushed in a cold porcelain mortar, placed in ice $\left(4^{\circ} \mathrm{C}\right)$. Next, phosphate buffered saline was added, boiled at $100^{\circ} \mathrm{C}$ for 30 minutes, and cooled down. Then, samples were centrifuged at $3000 \mathrm{rpm}$ for 10 minutes, the supernatant was collected, and the malondialdehyde (MDA) level was measured by the thiobarbituric acid (TBA) method with the spectrophotometer set a wavelength of $532 \mathrm{~nm}$.

\section{Endometrial histopathology}

Uterine tissue was dissected into $2-3$ $\mathrm{mm}$ transverse sections and then fixed in $10 \%$ buffered formalin. Uterine tissue was cut into a 3-5 $\mu \mathrm{m}$ thick section and stained for HE. Observation of endometrial thickness was captured using a dot slide camera of Olympus XC10, and measured using Olyvia software at a magnification of 400x. The result was calculated from observations of measurements of the average length between the inner and outer layers of the uterus in the 4 quadrants.

\section{Statistical analysis}

Statistical analysis was performed using the SPSS program (Version 20.0, SPSS Inc, IBM) with a one-way analysis of variance (ANOVA), followed by a post-hoc test leastsquares differences (LSD), and finally a correlation test with a Pearson product moment. The value was expressed as the mean \pm standard deviation (SD), the confidence 
interval was decided as $95 \%$, and p-value of $<0.05$ was considered statistically significant.

\section{RESULTS}

\section{Lead acetate regulated MDA level in rat uterine tissue}

This study showed that administration of lead acetate slightly increased the MDA level in the lead acetate group (Figure 1).

\section{Lead acetate mitigated endometrial thickness in rats}

Lead acetate reduced the thickness of the endometrium (Figure 2). This decrease was significantly different in line with increasing dose $(\mathrm{p}=0.005)$. In addition, alteration in the uterus is shown in Figures 2 and 3. Compared with the control group, the uterus of rats treated with $30 \mathrm{ppm}$ displayed a uniform reduction in the thickness of the endometrium (Figure 2B) whereas there was an extensive reduction in uterine thickness of rats that were administered $100 \mathrm{ppm}$ lead acetate (Figure 2C). Uterine changes in rats treated with $300 \mathrm{ppm}$ lead acetate were more severe and had a massive reduction in uterine thickness. Due to reduced thickness of the endometrium, a more spacious uterus was found in all parts of the uterus as shown in Figure 3.

\section{DISCUSSION}

General exposure of lead acetate could occur via inhalation, digestion, as well as dermal contact. Oral exposure is one of the crucial methods lead acetate infiltrates the bodies of humans and animals. About $5 \%-10 \%$ of lead acetate can be absorbed through the digestive mucosa whereas children can absorb 30\%-40\%. ${ }^{8}$ After these absorptions, the lead acetate will be discovered in the blood, especially in erythrocytes (99\%) and in serum $(1 \%) .{ }^{9}$ Lead acetate exposure could induce damage to erythrocytes by shortening their life cycle, especially in membrane transport cells, thus the ion transport across the cell membrane will be disturbed. Consequently, impairment of oxygen delivery to the body affects the comprehensive damage in all of part of the body. ${ }^{10}$

Lead acetate has the possibility of inducing oxidative stress leading to the generation of a high level of free radicals and the reduction of the antioxidant reaction. In this study, we assessed the effect of lead acetate administration on oxidative change as well as its influence on reproductive organ alteration in rats. Ayala et al showed that lead acetate administration leads to

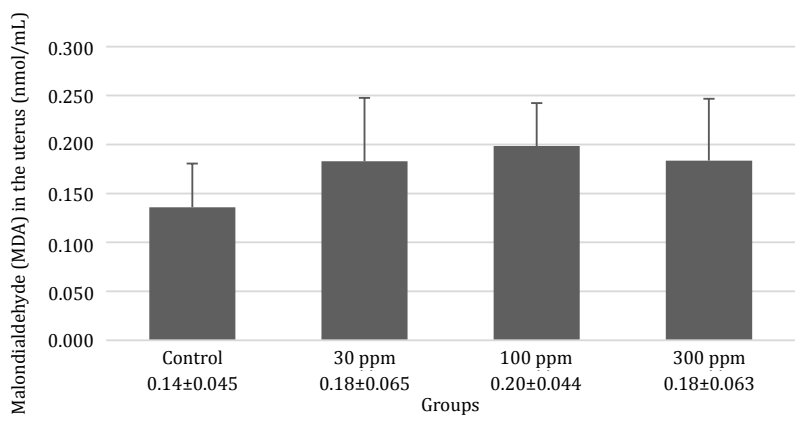

Figure 1. Evaluation of MDA levels in rats following 30 days post-exposure at $0,30,100$, and $300 \mathrm{ppm}$ in drinking water. Data are presented as mean \pm standard error with $p=0.255$
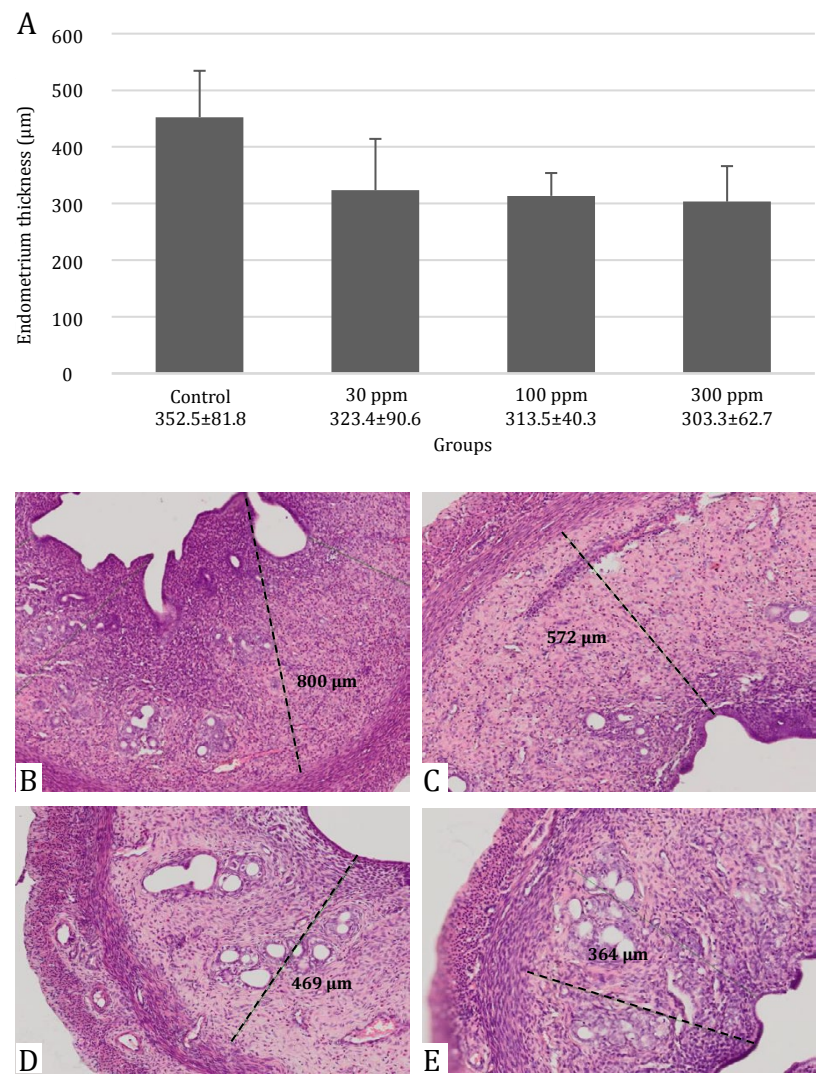

Figure 2. Evaluation of endometrial thickness in rats following 30 days post-exposure at 30,100 , and $300 \mathrm{ppm}$ in drinking water. Data are presented as mean \pm standard deviation with $\mathrm{p}=0.005$ : (A) Box graph representing endometrial thickness in each group with ${ }^{*} \mathrm{p}=0.005$; (B) Control group; (C) Exposure of lead acetate $30 \mathrm{ppm}$; (D) Exposure of lead acetate 100 ppm; (E) Exposure of lead acetate $300 \mathrm{ppm}$ 

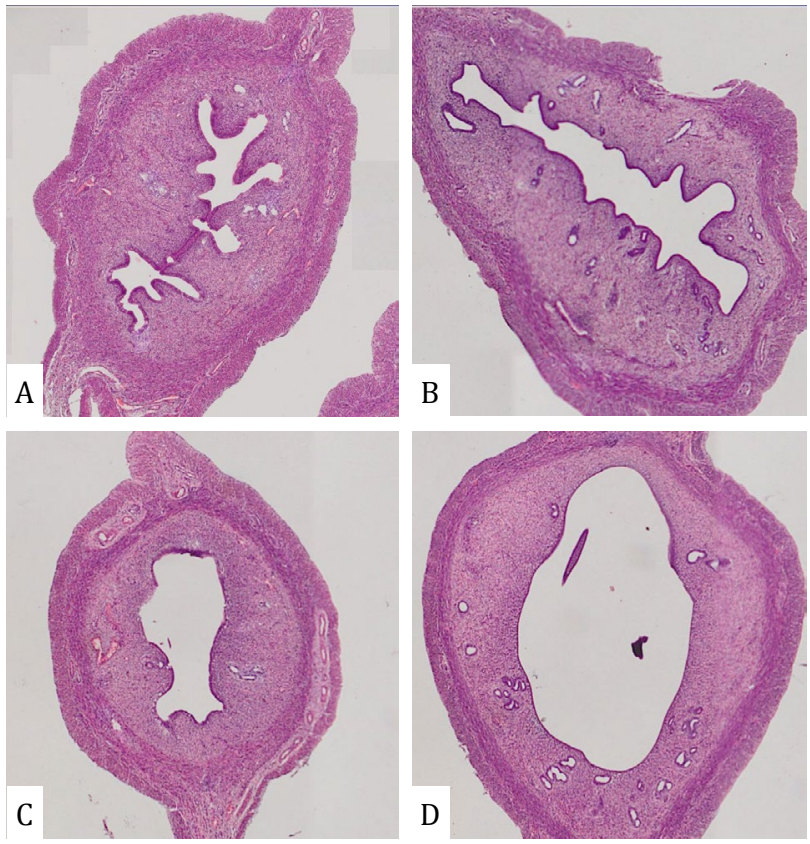

Figure 3. Lumen of endometrium in rats with lead acetate exposure (HE X 400): (A) Control group; (B) Exposure of lead acetate $30 \mathrm{ppm}$; (C) Exposure of lead acetate $100 \mathrm{ppm}$; (E) Exposure of lead acetate 300 ppm

an increased oxidative stress, MDA is discovered during the process of polyunsaturated fatty acid peroxidation in the cell as the final product that is produced when exposed to an environment with a high level of free radicals including lead acetate. ${ }^{6}$ This study demonstrated that the exposure of lead acetate orally could unstably increase the MDA level in the uterus of rats that were among experimental groups. In addition, during the statistical analysis, we found that there was no significant difference between the control group and treatment groups (and, therefore, excluded this as the pathway of oxidative stress in this study). The sources of these discrepancies, including variation in sample preparation, dosedependent manner, as well as the period of lead acetate exposure could be the main reason of this result In addition, with the higher dose of lead acetate exposure, the body will construct a specific mechanism to disguise MDA production by secreting metallothionein (MT). MT both acts as an antioxidant and binds heavy metals. Consequently, at a higher dose of lead acetate exposure, the MDA level will be suppressed at a relatively constant level. ${ }^{9}$

Endometrial thickness showed a significant decrease $(p=0,005)$ as the dose of lead acetate was progressively increased from 30,100 , and $300 \mathrm{ppm}$ orally in rats as shown in Figure 2. Lead acetate tends to impair all aspects of reproductive organs including the endometrium, myometrium, and perimetrium due to the inactivation of many uterine glands or altering uterine glandular secretion. An imbalance in the environment developed because of the defect of enzymes, growth factors, cytokines, lymphokines, hormones, and transport proteins.,11 Moreover, the thinness of the endometrium is also shown in the Figure 3 and reflects the thickness of the endometrium in the whole uterus; thus, a more spacious uterus was found and the reduce the probability of nidation during the window of implantation. ${ }^{12}$ In humans, a thin endometrium will decrease the probability of achieving successful in vitro fertilization (IVF) rates. For this reason, increasing the thickness of the endometrium is necessary to obtain an optimal pregnancy outcome. ${ }^{13-15}$

Direct prevention is difficult to achieve because of a widespread of lead acetate in the water that is used for drinking, cooking, as well as natural habitat for fish in Indonesia. Nevertheless, the prevention program to mitigate exposure of lead acetate should be recommended for implementation because of the damaging effects of lowering the quality of reproductive organs. ${ }^{3}$ However, our study has a limitation. While observing the MDA level in the uterus of rats exposed to lead acetate, the results indicated that the MDA level increased along with an rise of the lead acetate dose; however, it was not statistically significant. We believe that this goal is important, but could be accomplished by using chronic lead acetate exposure with a more definitive result.

In conclusion, lead acetate exposure in rats reduce in uterine thickness but had no specific effect on MDA level in the uterus when compared with the control group.

\section{Conflict of interest}

No conflict of interest in this study.

\section{REFERENCES}

1. Association of occupational environmental clinics. Medical management guidelines for lead-exposed adults. 2007;4-6. 
2. Riza F, Bambang AN, Kismartini. Water environment pollution of heavy metals $\mathrm{Pb}, \mathrm{Cd}$ and $\mathrm{Hg}$ in Jepara Kartini beach Central Java, Indonesia. Res J Marine Sci. 2016;4(1):1-4.

3. WHO. Lead in drinking-water background document for development of WHO guidelines for drinking-water quality. 2011;2:5-7.

4. Nakade UP, Garg SK, Sharma A, Choudhury S, Yadav RS, Gupta K, et al. Lead-induced adverse effects on the reproductive system of rats with particular reference to histopathological changes in uterus. Indian J Pharmacol. 2015;47(1):22-6.

5. Rao F, Zhai Y, Sun F. Punicalagin mollifies lead acetateinduced oxidative imbalance in male reproductive system. Int J Mol Sci. 2016;17(8):1269.

6. Ayala A, Muñoz MF, Argüelles S. Lipid peroxidation: production, metabolism, and signaling mechanisms of malondialdehyde and 4-hydroxy-2-nonenal. Oxid Med Cell Longev. 2014;2014:360438.

7. Anderson M, Aron DC, Badell ML, Bikle DD, Braunstein GD, Carroll TB, et al. Hypothalamus and pituitary glands. In: Gardner DG, Shoback D, editors. Greenspan's basic and clinical endocrinology. $9^{\text {th }}$ ed. New York: Mc Graw Hill Company; 2011.p.541-3

8. American council on science and health. Multiple chemical sensitivity. 2012;2-3.

9. Flora G, Gupta D, Tiwari A. Toxicity of lead: a review with recent updates. Interdiscip Toxicol. 2012;5(2):47-58.

10. Mohanty JG, Nagababu E, Rifkind JM. Red blood cell oxidative stress impairs oxygen delivery and induces red blood cell aging. Front Physiol. 2014;5:84.

11. Dumitrescu E, Chiurciu V, Muselin F, Popescu R, Brezovan D, Cristina RT. Effects of long-term exposure of female rats to low levels of lead: ovary and uterus histological architecture changes. Turk J Biol. 2015;39(2):284-9.

12. Qureshi N, Sharma R. Lead toxicity and infertility in female swiss mice: a review. Univers J Environ Res Technol. 2012;2(2):1849-61.

13. Sokol RZ, Wang S, Wan YY, Stanczyk FZ, Gentzschein E, Chapin RE. Long-term, low-dose lead exposure alters the gonadotropin-releasing hormone system in the male rat. Environ Health Perspect. 2002;110(9): 871-4.

14. Baradwan S, Shafi D, Baradwan A, Bashir MS, Al-Jaroudi D. The effect of endometrial thickness on pregnancy outcome in patients with Asherman's syndrome posthysteroscopic adhesiolysis. Int J Womens Health. 2018;10:77-82.

15. Chen X, Chen SI. Successful pregnancy in recurrent thin endometrium with new uses for an old drug. J IVF Reprod Med Genet. 2013;1(2):110. 